\title{
RECUPERAÇÃO DE ÁREAS IMPACTADAS PELA EXTRAÇÃO DE ARGILA ATRAVÉS DA PRODUÇÃO DE MUDAS DE ESPÉCIES ARBÓREAS INOCULADAS COM FUNGOS MICORRÍZICOS ARBUSCULARES
}

\author{
Eliade Rocha dos Santosi'; Andréa Hentz de Mello \\ ${ }^{1}$ Discente do curso de Agronomia, Faculdade de Ciências Agrárias de Marabá (FCAM), Universidade Federal do Pará \\ (UFPA), Marabá, Pará. E-mail: eliade_rs@ @otmail.com. \\ ${ }^{2}$ Prof. ${ }^{a}$, D.Sc., FCAM, UFPA. Email: andreahentz@ufpa.com.
}

RESUMO: A exploração de argila na cidade de Marabá tem causado uma série de impactos negativos ao meio biofísico. Tais impactos teriam sido minimizados mediante aplicação de medidas de prevenção e mitigação que devem acompanhar a instalação e operação de tais projetos, como a construção de muros de contenção de rejeitos, plantio de cercas vivas, fechamento das crateras abandonadas e a aplicação rigorosa da legislação ambiental. Por outro lado, existem procedimentos que podem ser aplicados a partir da exaustão da jazida, notadamente a regeneração natural, a reabilitação e a restauração, termos que possuem significados e conseqüências ambientais distintas. A regeneração natural é menos onerosa, contudo, pode resultar tanto num regime de sucessão vegetacional adequado como acentuar o estado de degradação. O processo de restauração consiste na recuperação da área em termos de condições de uso semelhantes ou idênticas àquelas que se processavam antes da exploração, ao passo que a reabilitação tem por intuito criar uma nova possibilidade de uso para o setor outrora explorado. Diante da necessidade da recuperação do referido ecossistemas, este trabalho tem como objetivo geral a produção de mudas arbóreas nativas inoculadas com fungos micorrízicos arbusculares (FMA's) para uso segundo os preceitos da reabilitação. Como objetivos específicos: Identificar e isolar FMA's da área de extração de argila; identificar e isolar FMA's de solos da região sudeste do Pará; produzir inóculo através do cultivo armadilha com Brachiaria brizantha e produzir mudas de espécies florestais nativas. O inóculo de FMA's será produzido através do cultivo armadilha com Brachiaria brizantha em areia de praia ao qual só será fornecida água três vezes ao dia no período de germinação até atingir $15 \mathrm{~cm}$ de altura em casa de vegetação. A extração de esporos de FMA's do solo consiste basicamente em extraí-los de $50 \mathrm{~g}$ de solo pela técnica de peneiramento úmido de Gerdemann e Nicolson e centrifugação em água e sacarose a $40 \%$. As espécies nativas e arbóreas inoculadas com fungos micorrízicos arbusculares serão escolhidas, juntamente com a população, em uma pesquisa de opinião pública, bem como através de registros botânicos da área de estudo. As sementes utilizadas na produção de mudas passarão pelo processo de quebra de dormência, efetuada de acordo com a necessidade de cada espécie. As mudas serão produzidas em sacos plásticos, bandejas e tubetes, com substrato contendo solo do local de extração da argila e vermiculita. Serão semeadas duas sementes por recipiente. A rega será efetuada três vezes ao dia. Aos 120 dias após a germinação, as mudas serão levadas para as áreas degradadas a fim de reabilitá-las. A situação almejada em todas as áreas que este trabalho se propõe tratar, comporta a convivência, num mesmo espaço, de uma pequena área de conservação limitada pelo talude da lavra, conjugados a novos ambientes que tendem a proporcionar um quadro paisagístico mais nobre, estabelecendo uma relação de complementaridade em usos diferenciados a serem engendrados pela presente proposta de reabilitação, de execução simples, que não interfere na organização do espaço adjacente e que recupera a função social e ambiental da área.

PALAVRAS-CHAVE: Exploração de argila, recuperação paisagística, insumos biológicos. 